\title{
Kerapatan Hutan Mangrove Berbasis Data Penginderaan Jauh di Estuari Perancak Kabupaten Jembrana-Bali
}

\author{
I Made Putra Kresnabayu a*, I Dewa Nyoman Nurweda Putra a, Yulianto Suteja a \\ a Program Studi Ilmu Kelautan, Fakultas Kelautan dan Perikanan, Universitas Udayana, Kampus UNUD Bukit Jimbaran, Bali 80361, Indonesia \\ *Penulis koresponden. Tel.: +62-822-3629-7390 \\ Alamat e-mail: pkresna2@gmail.com
}

Diterima (received) 25 Mei 2017; disetujui (accepted) 23 Agustus 2017; tersedia secara online (available online) 24 Agustus 2017

\begin{abstract}
The mangrove ecosystem is one of the objects that can be identified by using remote sensing technology. The geographical location of the mangrove ecosystem located in the land and sea transition areas provides a distinctive recording effect when compared to other land vegetation objects. Remote sensing information about vegetation density is useful for various needs such as estimation of the availability of wood fuel biomass, succession stages, forest degradation and so on. This study aims to map the mangrove density using NDVI mangrove vegetation index from Landsat 8 image in Estuari Perancak, Jembrana, Bali. The study was conducted on August 20, 2016 until August 25,2016 . The analysis used is correlation analysis and t-Test analysis. Based on the results of the study, it was found that the density class was rare, medium and tight. The density class rarely has a pixel value range from 0.4765 to 0.6128 , the medium density class has a pixel value range of 0.6128 to 0.7093 , and the dense or dense density has a pixel value range of 0.7093 to 0.7947 . The dominant mangrove species is Rhizopora sp. The linear regression equation in the above figure shows $y=0.679 x+0.438$ and with the correlation ( $r$ ) of 0.9642 . This means that the density of mangroves and NDVI is directly proportional. Where the higher the value of mangrove density, the higher the value of NDVI and reserve.
\end{abstract}

Keywords: corelation; mangrove density; NDVI

\begin{abstract}
Abstrak
Ekosistem mangrove adalah salah satu obyek yang bisa diidentifikasi dengan menggunakan teknologi penginderaan jauh. Letak geografis ekosistem mangrove yang berada pada daerah peralihan darat dan laut memberikan efek perekaman yang khas jika dibandingkan obyek vegetasi darat lainnya. Informasi penginderaan jauh mengenai kerapatan vegetasi berguna untuk berbagai kebutuhan seperti misalnya estimasi kertersediaan biomassa kayu bakar, tahap-tahap suksesi, kerusakan hutan dan sebagainya. Penelitian ini bertujuan untuk memetakan kerapatan mangrove menggunakan indeks vegetasi mangrove NDVI dari citra Landsat 8 di daerah Estuari Perancak, Jembrana, Bali. Waktu penelitian dilakukan pada tanggal 20 Agustus 2016 sampai dengan 25 Agustus 2016. Analisis yang diguakan adalah analisis korelasi dan analisis Uji-t. Berdasarkan hasil penelitian, didapatkan kelas kerapatan jarang, sedang dan rapat. Kelas kerapatan jarang memiliki rentang nilai pixel dari 0.4765 sampai 0.6128 , kelas kerapatan sedang memiliki rentang nilai pixel 0.6128 sampai 0.7093 , dan kerapatan padat atau rapat memiliki rentang nilai pixel 0.7093 sampai 0.7947. Jenis mangrove yang mendominasi adalah jenis Rhizopora sp. Persamaan regresi linier pada gambar diatas menunjukan $y=0.679 x+0.438$ dan korelasi $(r)$ sebesar 0.9642 . Hal ini berarti kerapatan mangrove dan NDVI berbanding lurus. Dimana semakin tinggi nilai kerapatan mangrove maka semakin tinggi pula nilai NDVI maupun sebaliknya.
\end{abstract}

Kata Kunci: kerapatan mangrove; korelasi; NDVI

\section{Pendahuluan}

Ekosistem hutan mangrove merupakan ekosistem pendukung utama bagi kehidupan di wilayah pesisir (Kathiresan, 2012; Brander et al., 2012). Secara ekologi hutan mangrove mempunyai peranan yang penting seperti peredam gelombang dan angin, pelindung pantai dari abrasi, penahan 
lumpur dan sedimen, sebagai daerah asuhan dan tempat mencari makan, tempat pemijahan biota perairan dan lain sebagainya (Bengen, 2001). Semakin meningkatnya pembangunan ditambah dengan meningkatnya kebutuhan hidup di wilayah pesisir, akan berakibat terjadinya tekanan terhadap sumberdaya alam di wilayah pesisir (Kartikasari, 2015). Seiring dengan perubahan penggunaan lahan yang relatif cepat dalam suatu wilayah yang berkembang, sehingga diperlukan penataan yang lebih baik seberapa besar kebutuhan mangrove untuk wilayah tersebut (Giri et al., 2011; Singh et al., 2014).

Guna mendukung keberlangsungan hutan mangrove maka dibutuhkan data dan informasi. Data dan informasi dapat diperoleh salah satunya dengan memanfaatkan teknologi penginderaan jauh (Kuenzer et al., 2011; Adam et al., 2010). Salah satu data penginderaan jauh yang dapat dimanfaatkan untuk memantau hutan mangrove adalah Citra Landsat 8 (Pastor-Guzman et al., 2015; El-Askary et al., 2014). Informasi penginderaan jauh mengenai kerapatan vegetasi berguna untuk berbagai kebutuhan seperti misalnya estimasi kertersediaan biomassa kayu bakar, tahap-tahap suksesi, kerusakan hutan dan sebagainya (Richards and Friess, 2016). Oleh karena itu, informasi kerapatan vegetasi dapat dijadikan data serta untuk pendukung studi selanjutnya.
Adapun tujuan dari penelitian ini adalah untuk memetakan kerapatan hutan mangrove pada hutan mangrove di Estuari Perancak.

\section{Metode Penelitian}

\subsection{Lokasi dan Waktu}

Penelitian ini berlokasi di Estuari Perancak, yang secara administratif berada di Kecamatan Jembrana, Kabupaten Jembrana, Provinsi Bali. Batasan wilayah penelitian berada pada dua desa, yaitu Desa Budeng dan Desa Perancak. Dengan kordinat lokasi $8^{\circ} 23.669$ Lintang Selatan dan $114^{\circ}$ 37.466 Bujur Timur. Waktu penelitian dilakukan pada tanggal 20 Agustus 2016 sampai dengan 25 Agustus 2016 (Gambar 1).

\subsection{Alat dan Bahan}

Alat yang digunakan dalam pengambilan data penelitian adala sebagai berikut :

1. Seperangkat PC

2. Transek

3. GPS

4. Alat Tulis

Adapun bahan yang digunakan dalam penelitian adalah sebagai berikut:

1. Citra Satelit Landsat 8 dengan resolusi citra 30

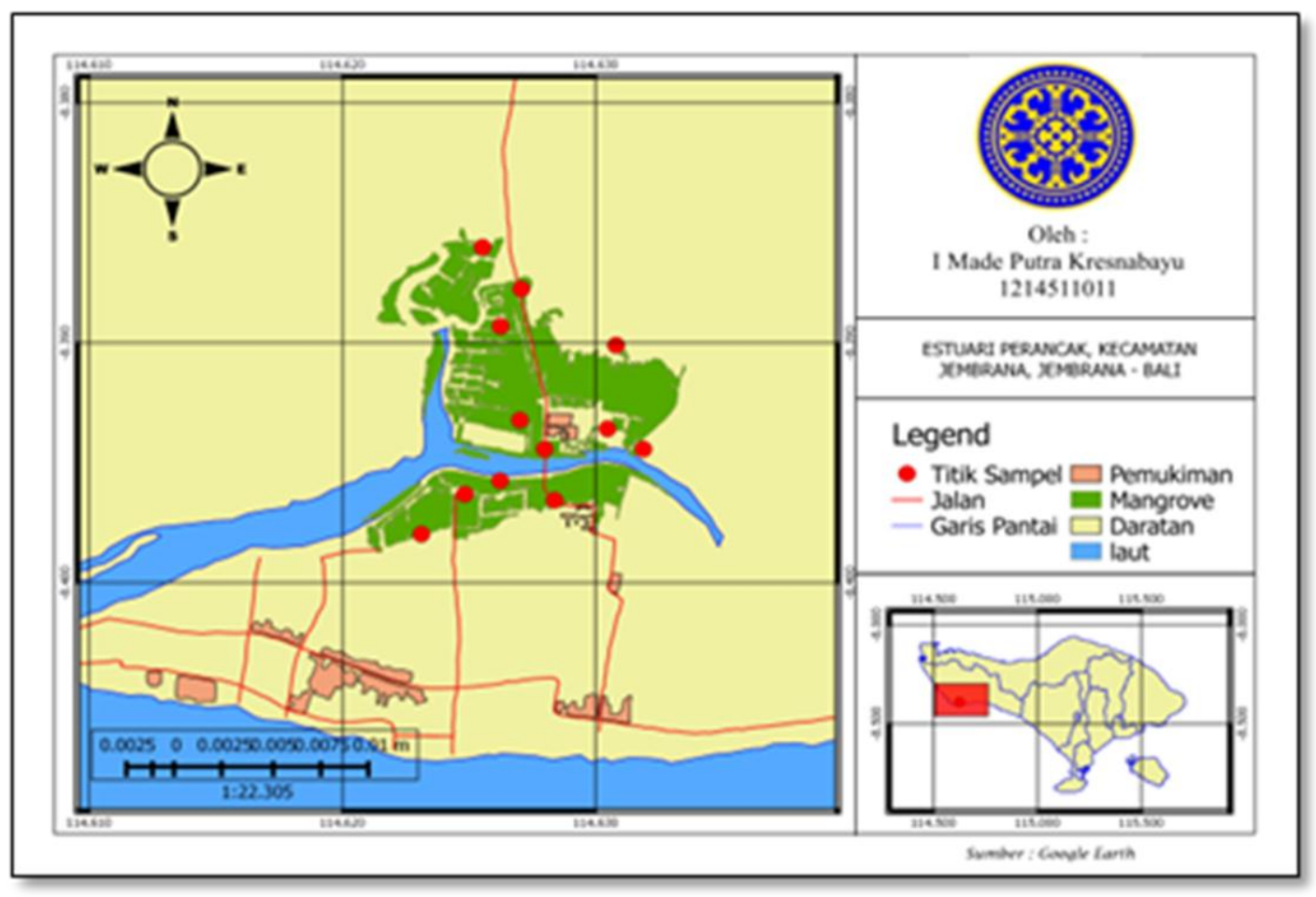

Gambar 1. Peta Lokasi Penelitian 
meter

2. Data Lapangan (Ground Chek)

\subsection{Metode}

\subsubsection{Pengolahan Data Pengindraan Jauh}

Salah satu analisis indeks vegetasi adalah dengan metode Normalized Difference Vegetation Index (NDVI) yang bertujuan untuk menentukan tingkat kerapatan kanopi mangrove. Analisis ini menggunakan metode rasio ternormalisasi (normalized ratio) dengan kanal NIR (Near Infrared) dan RED pada Landsat 8. Nilai indeks vegetasi NDVI dapat diformulasikan persamaan (1) (Waas, 2010) :

\section{NDVI=NIR -Red / NIR+Red}

Keterangan :

$\mathrm{NIR}=$ Band 5

Red $=$ Band 4

\subsubsection{Pengambilan Data Lapangan}

Metode yang digunakan untuk memperoleh data kerapatan vegetasi mangrove dilapangan adalah metode transek kuadrat dengan ukuran 10 x 10 m. Pada penelitian ini petak contoh dibuat bujur sangkar. Transek 10 x 10 m digunakan untuk menghitung jumlah tegakan mangrove tingkat pohon dengan tinggi $>1 \mathrm{~m}$ dan diameter batang $>$ $4 \mathrm{~cm}$. Analisis data lapang dengan menghitung kerapatan menggunakan persamaan (2) (Di) (Bengen in Sobatnu dan Fery, 2016) :

$\mathrm{Di}=\mathrm{ni} / \mathrm{A}$

Keterangan :

$\mathrm{ni}=$ Jumlah total tegakan ke-i (ind)

$\mathrm{A}=$ Luas area plot pengamatan $\left(\mathrm{m}^{2}\right)$

\subsubsection{Analisis Korelasi}

Analisis korelasi adalah metode statistika yang digunakan untuk menentukan kuatnya atau derajat hubungan linier antara dua variabel atau lebih. Semakin nyata hubungan linier (garis lurus), maka semakin kuat atau tinggi derajat hubungan garis lurus antara kedua variabel atau lebih. Ukuran untuk derajat hubungan garis lurus ini dinamakan koefisien korelasi.

Analisis korelasi digunakan untuk mengetahui hubungan satu variabel dengan variabel lain.
Dimana korelasi dilambangkan dengan (r). Dengan ketentuan nilai dari $\mathrm{r}$ tidak lebih dari 1 dan kurang dari $-1(-1 \leq r \leq 1)$. Apabila nilai $r=-1$ artinya korelasi negatif sempurna, $r=0$ artinya tidak ada korelasi dan $\mathrm{r}=1$ artinya korelasinya sangat kuat.

Korelasi Produk Moment dikembangkan oleh Karl Pearson sehingga koefien yang diperoleh sering disebut dengan korelasi pearson. Istilah product moment digunakan kerena teknis tersebut didasarkan kepada cross product $\mathrm{x}$ dan y sebagai skor simpangan dari moment pertama (rata-rata) masing-masing peubah. Korelasi Pearson dapat dirumuskan pada persamaan (3) (Istiarini dan Sukanti, 2012) :

$\mathrm{r}_{\mathrm{xy}}=\frac{n \sum x y-\sum x \sum y}{\sqrt{n \sum x^{2}-\left(\sum x\right)^{2}} \sqrt{n \sum y^{2}-\left(\sum y\right)^{2}}}$

Keterangan :

$\mathrm{n} \quad=$ banyaknya pasangan data $\mathrm{x}$ dan $\mathrm{y}$

$\sum x=$ total jumlah dari variabel $\mathrm{x}$

$\sum y=$ total jumlah dari variabel $\mathrm{y}$

$\sum x^{2}=$ kuadrat dari total jumlah varibel $\mathrm{x}$

$\sum y=$ kuadrat dari total jumlah variabel $\mathrm{y}$

$\sum x y=$ hasil perkalian dari total jumlah variabel $\mathrm{x}$ dan variabel $\mathrm{y}$

\subsubsection{Analisis Bivariat}

Analisa bivariat dilakukan pada dua variabel untuk mengetahui adanya hubungan atau korelasi. Analisis Bivariat yang digunakan adalah Uji-T. Uji$\mathrm{T}$ (t-test) adalah jenis pengujian statistika untuk mengetahui apakah ada perbedaan dari nilai yang diperkirakan dengan nilai hasil perhitungan statistika. Dalam penelitian kali ini digunakan Uji$\mathrm{T}$ bebas ( $t$-test independent).

Independent sample t-test adalah jenis uji statistika yang bertujuan untuk membandingkan rata-rata dua grup yang tidak saling berpasangan atau tidak saling berkaitan. Tidak saling berpasangan dapat diartikan bahwa penelitian dilakukan untuk dua subjek sampel yang berbeda.

Data dinyatakan memiliki varian yang sama (equal variance) atau sebaliknya varian data dinyatakan tidak sama (unequal variance). Bentuk varian kedua kelompok data akan berpengaruh pada nilai standar error yang akhirnya akan membedakan rumus pengujiannya. Uji $t$ untuk varian yang sama (equal variance) menggunakan persamaan (4) dan (5) : 


$$
\begin{aligned}
S^{2} & =\frac{\sum_{i=1}^{n}\left(x_{i}-x\right)^{2}}{(n-1)} \\
t & =\frac{X_{1}-x_{2}}{\sqrt{\frac{\left(n_{1}-1\right) S_{1}^{2}+\left(n_{2}-1\right) S_{2}^{2}}{n_{1}+n_{2}-2}\left(\frac{1}{n_{1}}+\frac{1}{n_{2}}\right)}}
\end{aligned}
$$

Uji t untuk varian yang berbeda (unequal variance) menggunakan rumus manual Separated Varians menggunakan persamaan (6) :

$t=\frac{\mathrm{X}_{1}-\mathrm{X}_{2}}{\sqrt{\frac{s_{1}^{2}}{n_{1}}+\frac{s_{2}^{2}}{n_{2}}}}$

Keterangan :

$$
\begin{array}{ll}
n_{1} & =\text { jumlah sampel } 1 \\
n_{2} & =\text { jumlah sampel } 2 \\
\mathrm{x}_{1} & =\text { rata-rata sampel } 1 \\
\mathrm{x}_{2} & =\text { rata-rata sampel } 2 \\
S_{1}^{2} & =\text { varian sampel } 1 \\
S_{2}^{2} & =\text { varian sampel } 2
\end{array}
$$

\section{Hasil dan Pembahasan}

\subsection{Kerapatan Vegetasi Mangrove}

Hasil pengolahan data Landsat 8 dapat digunakan untuk menghitung luas tutupan hutan mangrove ataupun kerapatan dari hutan mangrove. Dari metode tersebut didapatkan jumlah mangrove per titik sampling (Gambar 2).

Berdasarkan data diatas menunjukan jumlah mangrove pertitik sampel yang paling tinggi berada di titik sampel 12 yaitu $0.482 \mathrm{ind} / \mathrm{m}^{2}$ dan paling rendah berada pada titik 2 yaitu sebesar $0.114 \mathrm{ind} / \mathrm{m}^{2}$ dengan rata-rata sebesar $0.304 \mathrm{ind} / \mathrm{m}^{2}$. Perbedaan nilai tersebut digunakan untuk mengklasifikasi mangrove berdasarkan kerapatan yang akan dihubungkan dengan analisis indeks vegetasi. Dari hasil indeks vegetasi dalam hal ini menggunakan Normalized Difference Vegetation Indeks (NDVI) pada hutan mangrove yang berada di estuari perancak yaitu memiliki rentang nilai sebesar 0.4765 sampai 0.7947 .

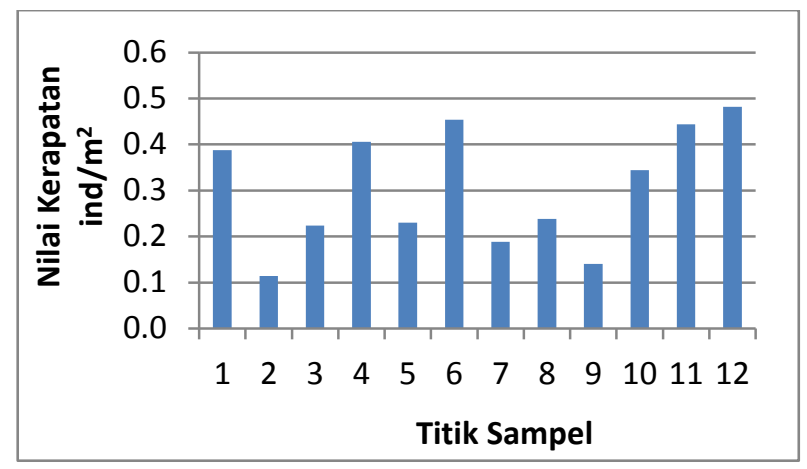

Gambar 2. Jumlah mangrove pertitik sampel

Kelas kerapatan jarang memiliki rentang nilai pixel dari 0.4765 sampai 0.6128 , kelas kerapatan sedang memiliki rentang nilai pixel 0.6128 sampai 0.7093, dan kerapatan padat atau rapat memiliki rentang nilai pixel 0.7093 sampai 0.7947 (Gambar 3). Data tersebut juga didukung oleh penelitian yang telah dilakukan oleh Wulandari dan Farid (2013), dimana rentan nilai NDVI untuk hutan

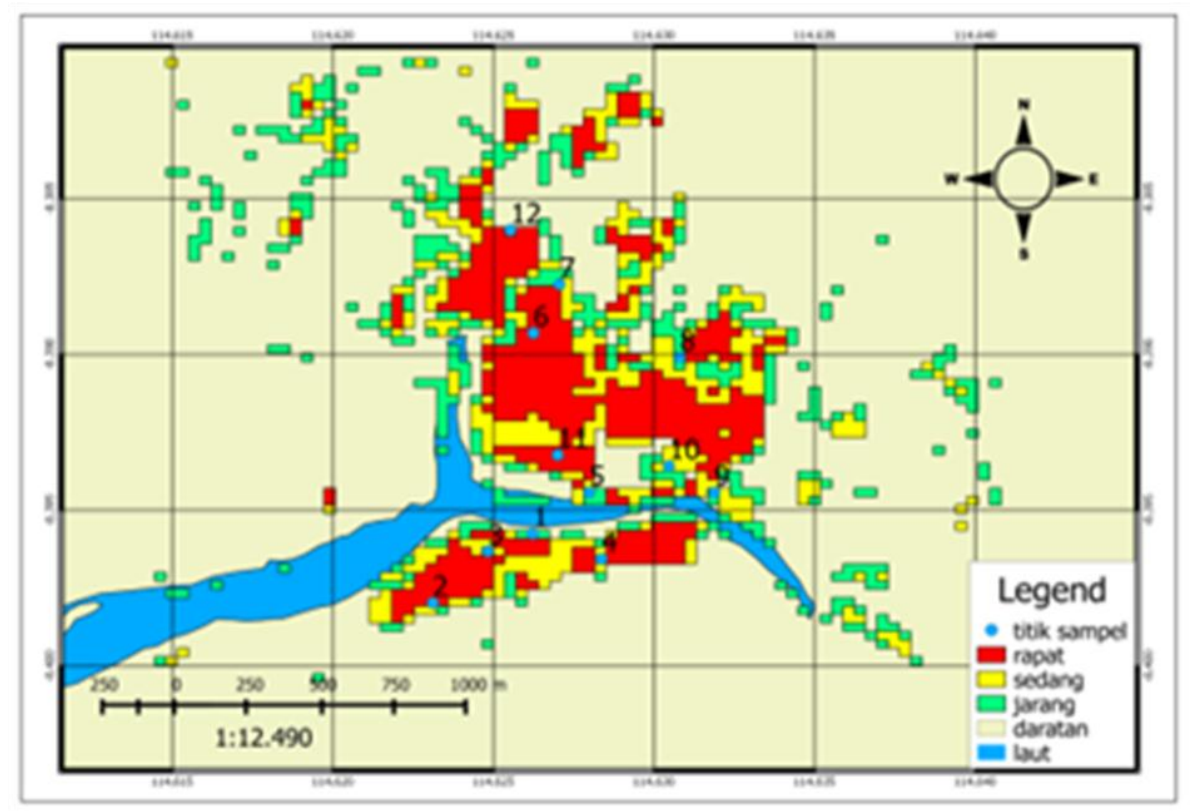

Gambar 3. Peta Distribusi Kerapatan Vegetasi Mangrove 
yaitu berkisar antara $0.3-0.8$. Senada dengan penelitian yang dilakukan oleh Kartikasari (2015) yang berlokasi di Estuari Perancak, dimana rentang nilai NDVI untuk vegetasi mangrove berkisar antara $0.4-0.8$.

Dapat dilihat pada Gambar 3 kerapatan mangrove yang rapat lebih mendominasi dibandingkan dengan kerapatan sedang dan jarang. Hal tersebut diduga karena substrat untuk tumbuh dan berkembang sangat baik serta sedikitnya gangguan terhadap ekosistem mangrove. Sehingga, mangrove tumbuh sangat subur di daerah tersebut. Untuk penyebarannya mangrove yang rapat berada di tengah vegetasi mangrove dan mangrove yang sedang mengelilingi mangrove yang rapat. Sementara itu, untuk mangrove yang jarang berada di pinggir vegetasi atau lebih banyak tumbuh di sisi sungai atau laut.

Pada kerapatan padat atau rapat diperkirakan merupakan mangrove alami yang memang sudah tumbuh sangat lama di daerah tersebut akan tetapi tidak semua kerapatan yang padat merupakan mangrove alami. Terdapat pula mangrove hasil dari konversi lahan yang kerapatannya padat. Begitu pula pada kerapatan sedang. Sulit untuk membedakan mangrove alami dan buatan, diperkirakan konversi lahan menjadi lahan mangrove sudah berlangsung lama yang menyebabkan hutan mangrove buatan menyerupai hutan mangrove alami.

Selain itu, diduga pada saat penanam kembali mangrove jarak antar mangrove tidak terlampau jauh sehingga mangrove hasil konversi menjadi rapat. Pada kerapatan jarang lebih didominasi oleh mangrove yang baru tumbuh baik itu secara alami maupun hasil konversi. Resolusi citra yang rendah dari citra Landsat 8 juga mengakibatkan sulitnya membedakan mangrove alami dan buatan. Hal ini juga didukung oleh penelitian yang telah dilakukan oleh Prameswari (2015) yang berlokasi di Estuari Perancak, dimana sulitnya membedakan vegetasi mangrove dikarenakan wilayah kajian yang kecil dan resolusi dari citra yang rendah.

Adapun jenis mangrove yang terdapat pada tiap-tiap titik sampel dapat dilihat pada Tabel 3 dimana terdapat 2 sampai 3 jenis mangrove yang berbeda. Jenis Rhizopora sp mendominasi jenis mangrove dari 12 titik sampel. Senada dengan penelitian yang telah dilakukan oleh Mahasani
(2015) yang berlokasi di Estuari Perancak dimana jenis Rhizopora sp merupakan spesies yang paling banyak ditemukan.

Tabel 2.

Jenis Mangrove pada titik sampel

\begin{tabular}{cl}
\hline Titik Sampel & \multicolumn{1}{c}{ Jenis Mangrove } \\
\hline 1 & Rhizopora sp dan Soneratia \\
2 & Rhizopora sp \\
3 & Rhizopora sp dan Bruguera $s p$ \\
4 & Rhizopora sp \\
5 & Rhizopora $s p$ dan Soneratia $s p$ \\
6 & Rhizopora sp dan Avicenia $s p$ \\
7 & Soneratia sp dan Xylocarpus sp \\
8 & Rhizopora sp, Soneratia sp dan Avicenia sp \\
9 & Soneratia $s p$ dan Bruguera $s p$ \\
10 & Avicenia $s p$ \\
11 & Rhizopora $s p$ \\
12 & Rhizopora $s p$ \\
\hline
\end{tabular}

3.2 Analisis Hubungan antara NDVI dengan Kerapatan

Dari hasil perhitungan NDVI dengan kerapatan vegetasi dalam hal ini adalah kerapatan vegetasi mangrove. didapatkan grafik regresi seperti pada Gambar 4.

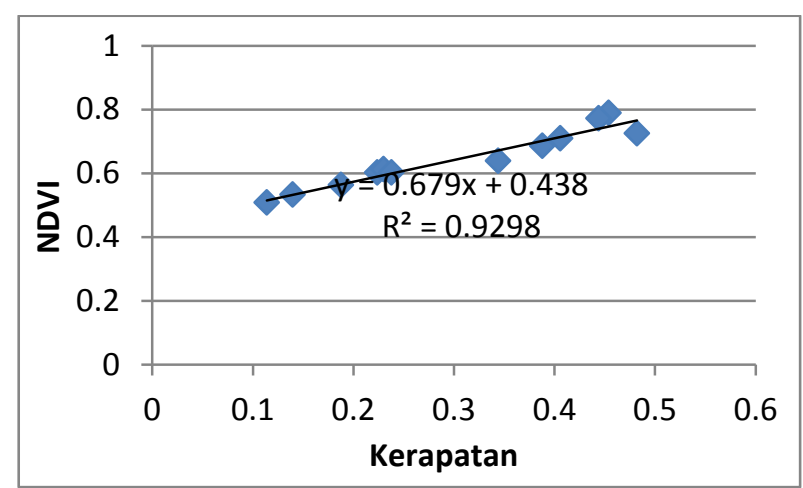

Gambar 4. Grafik Hubungan NDVI dengan Kerapatan

Persamaan regresi linier pada gambar diatas menunjukan nilai $\mathrm{y}=0.679 \mathrm{x}+0.438$ dimana $\mathrm{y}$ adalah NDVI dan $x$ merupakan hasil perhitungan kerapatan di lapangan yang menunjukan hubungan yang positif, artinya makin tinggi nilai $x$ maka makin besar pula nilai y. Korelasi (r) bernilai positif sebesar 0.929 yang menunjukan bahwa terjadi hubungan yang erat antara kerapatan mangrove dengan NDVI. Hal ini berarti kerapatan mangrove dan NDVI berbanding lurus. Dimana semakin tinggi nilai kerapatan mangrove maka semakin tinggi pula nilai NDVI maupun 
sebaliknya. Koefisien korelasi yang bertanda positif menunjukan hubungan yang satu arah antara NDVI dengan kerapatan. Senada dengan penelitian yang telah dilakukan oleh Kusumaningrum dan Sukojo (2013) menunjukan hubungan nilai NDVI pada citra dengan data kerapatan satu arah dengan $\mathrm{r}$ sebesar $0.82 \%$. Hal ini dipengaruhi oleh perbandingan sifat respon vegetasi terhadap pantulan sinar merah dan NIR yang dapat menghasilkan nilai dengan karakteristik khas yang dapat digunakan untuk memperkirakan kerapatan atau kondisi kanopi (kehijauan tanaman) (Kaswanto. 2010). Sehingga NDVI banyak digunakan untuk berkorelasi dengan banyak atribut ekosistem seperti produktivitas primer bersih, tutupan kanopi, tutupan lahan kosong dan lain-lain.

\section{Simpulan dan Saran}

Berdasarkan hasil dari pembahasan penelitian dapat disimpulkan yaitu kerapatan hutan mangrove di Estuari Perancak menggunakan metode NDVI memiliki rentang nilai sebesar 0.476472 sampai 0.794689 . Kelas kerapatan jarang memiliki rentang nilai pixel dari 0.4765 sampai 0.6128 , kelas kerapatan sedang memiliki rentang nilai pixel 0.6128 sampai 0.7093 , dan kerapatan padat atau rapat memiliki rentang nilai pixel 0.7093 sampai 0.7947. hasil perhitungan NDVI dengan kerapatan vegetasi dalam hal ini adalah kerapatan vegetasi mangrove. Hubungan kerapatan mangrove dengan NDVI berbanding lurus. Persamaan regresi linier menunjukan $\mathrm{y}=$ $0.679 x+0.438$ dan nilai $r$ sebesar 0.929 yang menunjukan terjadinya hubungan yang erat.

Saran yang dapat diberikan dalam penelitian ini yaitu diperlukan penelitian lanjutan sehingga dapat dilihat arah perkembangan kerapatan di Estuari Perancak.

\section{Daftar Pustaka}

Adam, E., Mutanga, O., \& Rugege, D. (2010). Multispectral and hyperspectral remote sensing for identification and mapping of wetland vegetation: a review. Wetlands Ecology and Management, 18(3), 281296.

Bengen, D. G. (2001). Sinopsis ekosistem dan sumberdaya alam pesisir dan laut serta prinsip pengelolaannya. Bogor, Indonesia; Pusat Kajian Sumberdaya Pesisir Dan Lautan Institut Pertanian Bogor.
Brander, L. M., Wagtendonk, A. J., Hussain, S. S., McVittie, A., Verburg, P. H., de Groot, R. S., \& van der Ploeg, S. (2012). Ecosystem service values for mangroves in Southeast Asia: A meta-analysis and value transfer application. Ecosystem Services, 1(1), 6269.

El-Askary, H., Abd El-Mawla, S. H., Li, J., El-Hattab, M. M., \& El-Raey, M. (2014). Change detection of coral reef habitat using Landsat-5 TM, Landsat 7 ETM+ and Landsat 8 OLI data in the Red Sea (Hurghada, Egypt). International Journal of Remote Sensing, 35(6), 23272346.

Giri, C., Ochieng, E., Tieszen, L. L., Zhu, Z., Singh, A., Loveland, T., Masek, J., \& Duke, N. (2011). Status and distribution of mangrove forests of the world using earth observation satellite data. Global Ecology and Biogeography, 20(1), 154-159.

Heriyanto, N. M., \& Subiandono, E. (2012). Komposisi dan Struktur Tegakan, Biomasa, dan Potensi Kandungan Karbon Hutan Mangrove di Taman Nasional Alas Purwo. Jurnal Penelitian Hutan dan Konservasi Alam, 9(1), 023-032.

Istiarini, R., \& Sukanti, S. (2012). Pengaruh Sertifikasi Guru dan Motivasi Kerja Guru Terhadap Kinerja Guru SMA Negeri 1 Sentolo Kabupaten Kulon Progo Tahun 2012. Jurnal Pendidikan Akuntansi Indonesia, 10(1), 98-113.

Kartikasari, A. D., \& Sukojo, B. M. (2015). Analisis Persebaran Ekosistem Hutan Mangrove Menggunakan Citra Landsat-8 Di Estuari Perancak Bali. Geoid, 11(1), 1-8.

Kaswanto, R. L. (2010). NDVI. [online], (http://kaswanto. staff.ipb.ac.id/ndvi/), [diakses: 6 januari 2017]

Kathiresan, K. (2012). Importance of Mangrove Ecosystem. International Journal of Marine Science, 2(10), 70-89.

Kuenzer, C., Bluemel, A., Gebhardt, S., Quoc, T. V., \& Dech, S. (2011). Remote sensing of mangrove ecosystems: A review. Remote Sensing, 3(5), 878-928.

Kusumaningrum, T. E., \& Sukojo, B. M. (2013). Analisa Kesehatan Mangrove Berdasarkan Nilai Normalized Difference Vegetation Index Menggunakan Citra ALOS AVNIR-2. Geoid, 9(2), 142-149.

Mahasani, I. G. A. I., Widagti, N., \& Karang, I. W. G. A. (2015). Estimasi persentase karbon organik di hutan mangrove bekas tambak, Perancak, Jembrana, Bali. Journal of Marine and Aquatic Sciences, 1(1), 14-18.

Pastor-Guzman, J., Atkinson, P. M., Dash, J., \& RiojaNieto, R. (2015). Spatiotemporal variation in mangrove chlorophyll concentration using Landsat 8 . Remote Sensing, 7(11), 14530-14558.

Prameswari, A. A. S. R., Hariyanto, T., \& Sidik, F. (2015). Analisis Indeks Vegetasi Mangrove Menggunakan Citra Satelit Alos Avnir-2 (Studi Kasus: Estuari Perancak, Bali). Geoid, 11(1), 40-45. 
Richards, D. R., \& Friess, D. A. (2016). Rates and drivers of mangrove deforestation in Southeast Asia, 20002012. Proceedings of the National Academy of Sciences, 113(2), 344-349.

Singh, S. K., Srivastava, P. K., Gupta, M., Thakur, J. K., \& Mukherjee, S. (2014). Appraisal of land use/land cover of mangrove forest ecosystem using support vector machine. Environmental earth sciences, 71(5), 2245-2255.

Sobatnu, F., \& Irawan, F. E. (2016). Kajian Tingkat Kerapatan Hutan Mangrove Menggunakan Teknologi Remote Sensing. Dalam Prosiding SNRT (Seminar Nasional Riset Terapan). Banjarmasin, Indonesia, 9-10 November 2016 (pp. D80-D89).
Sugirahayu, L dan Omo R. (2011). Perbandingan Simpana Karbon pada Beberapa Penutupan Lahan di Kabupaten Paser, Kalimantan Timur Berdasarkan Sifat Fisik dan Sifat Kimia Tanahnya. Jurnal Silvikultura Tropika, 2(3), 149-155.

Waas, H. J., \& Nababan, B. (2010). Pemetaan dan analisis index vegetasi mangrove di pulau Saparua, Maluku Tengah. Jurnal Ilmu dan Kelautan Tropis, 2(1), 50-58.

Wulandari, D., \& Samsu, F. (2013). Identifikasi Sebaran Dan Tingkat Kesuburan Mangrove Melalui Pemantauan Indeks Vegetasi Dari Satelit Landsat 7.0 ETM+ Menggunakan Fuzzy Logic (Studi Kasus Pantai Pesisir Timur Surabaya/Pamurbaya). Jurnal Neutrino, 6(1), 60-67.

(c) 2017 by the authors; licensee Udayana University, Indonesia. This article is an open access article distributed under the terms and conditions of the Creative Commons Attribution license (http://creativecommons.org/licenses/by/3.0/). 